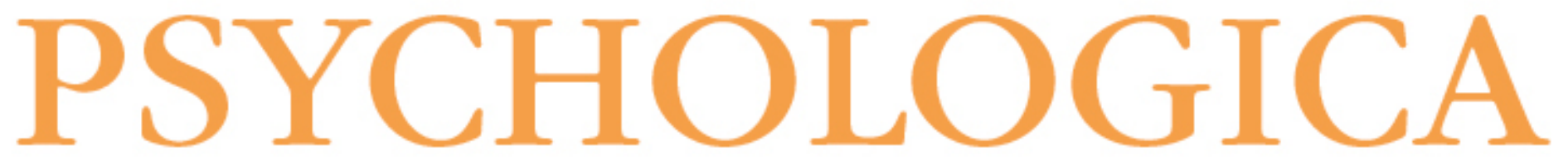

\title{
Auto-Compaixão: estudo da validação da versão portuguesa da Escala da Auto- Compaixão e da sua relação com as experiências adversas na infância, a comparação social e a psicopatologia
}

Autor(es): $\quad$ Castilho, Paula; Gouveia, José Pinto

Publicado por: Imprensa da Universidade de Coimbra

URL persistente:

URl:http://hdl.handle.net/10316.2/5577

DOI:

DOI:http://dx.doi.org/10.14195/1647-8606_54_8

Accessed : $\quad$ 26-Apr-2023 10:34:51

A navegação consulta e descarregamento dos títulos inseridos nas Bibliotecas Digitais UC Digitalis, UC Pombalina e UC Impactum, pressupõem a aceitação plena e sem reservas dos Termos e Condições de Uso destas Bibliotecas Digitais, disponíveis em https://digitalis.uc.pt/pt-pt/termos.

Conforme exposto nos referidos Termos e Condições de Uso, o descarregamento de títulos de acesso restrito requer uma licença válida de autorização devendo o utilizador aceder ao(s) documento(s) a partir de um endereço de IP da instituição detentora da supramencionada licença.

Ao utilizador é apenas permitido o descarregamento para uso pessoal, pelo que o emprego do(s) título(s) descarregado(s) para outro fim, designadamente comercial, carece de autorização do respetivo autor ou editor da obra.

$\mathrm{Na}$ medida em que todas as obras da UC Digitalis se encontram protegidas pelo Código do Direito de Autor e Direitos Conexos e demais legislação aplicável, toda a cópia, parcial ou total, deste documento, nos casos em que é legalmente admitida, deverá conter ou fazer-se acompanhar por este aviso. 


\section{NÚMERO 54}

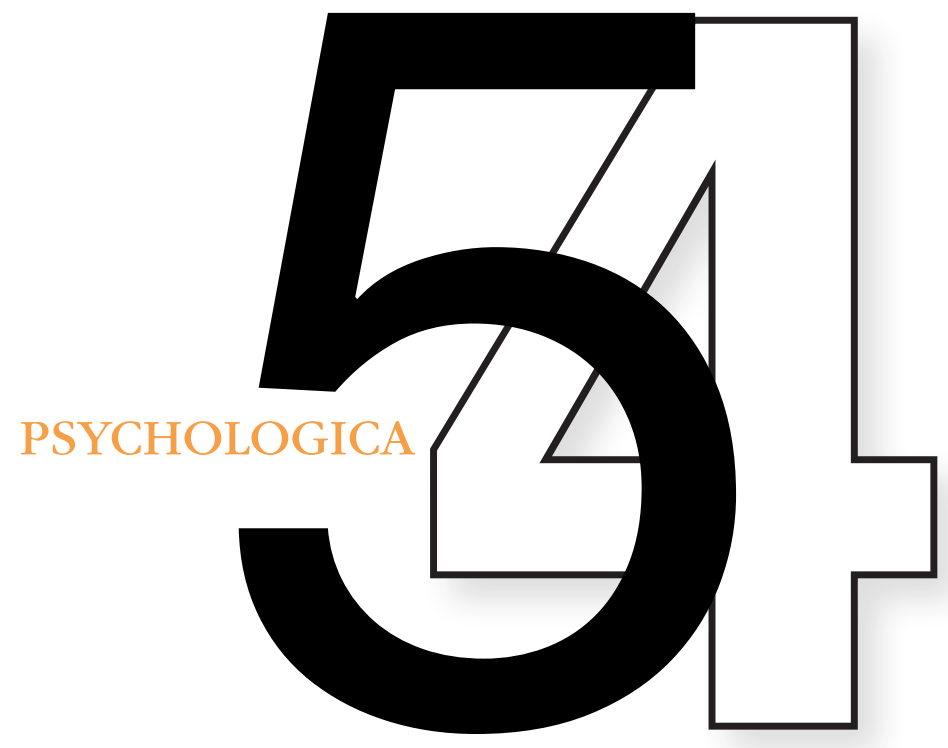

AVALIAÇÃO PSICOLÓGICA EM CONTEXTO CLÍNICO 


\title{
Auto-Compaixão: Estudo da validação da versão portuguesa da Escala da Auto-Compaixão e da sua relação com as experiências adversas na infância, a comparação social e a psicopatologia
}

\author{
Paula Castilho' \& José Pinto Gouveia²
}

\begin{abstract}
A Auto-Compaixão é uma estratégia de auto-regulação emocional com um efeito amortecedor no desenvolvimento da psicopatologia. O primeiro estudo apresenta as propriedades psicométricas da versão portuguesa da Escala da Auto-Compaixão (SelfCompassion Scale, SCS; Neff, 2003); as experiências adversas na infância associadas negativamente à auto-compaixão e a relação com a comparação social e psicopatologia, numa amostra de 631 estudantes universitários. Os valores de consistência interna, de estabilidade temporal e de validade convergente e divergente são satisfatórios. O segundo estudo mostra que o criticismo e desinteresse do pai (nos homens) e da mãe (nas mulheres) contribuem para auto-compaixão baixa. Esta é fundamental para a aceitação social, assim como a existência de uma mãe calorosa (nas mulheres). A sobre-identificação contribui para a depressão, nos homens, e o isolamento, a dificuldade em ser tolerante e amável consigo próprio e a sobre-identificação nas mulheres. A auto-compaixão e pais cuidadores protegem da depressão, nas mulheres.
\end{abstract}

PALAVRAS-CHAVE: Auto-compaixão; Propriedades psicométricas; Experiências negativas na infância; Comparação social; Sintomas depressivos.

\section{Introdução}

O conceito de Auto-Compaixão é antigo no pensamento filosófico Oriental, sendo relativamente recente na Psicologia Ocidental. Tem-se assistido, nos últimos anos, a um progressivo crescimento no diálogo entre o pensamento e filosofia oriental (Budismo, em particular) e a psicologia ocidental, o que tem contribuido para uma nova forma de compreender e lidar com a saúde mental, por um lado, e

\footnotetext{
1 Centro de Investigação do Núcleo de Estudos e Intervenção Cognitivo-Comportamental, Faculdade de Psicologia e de Ciências da Educação, Universidade de Coimbra, Portugal - paulacastilho@fpce.uc.pt 2 Coordenador do Centro de Investigação do Núcleo de Estudos e Intervenção Cognitivo-Comportamental, Faculdade de Psicologia e de Ciências da Educação, Universidade de Coimbra, Portugal; Professor Catedrático da Faculdade de Psicologia e Ciências da Educação da Universidade de Coimbra
} 
com o bem-estar, por outro lado (Epstein, 1995; Molino, 1998; Nisker, 1998; Rubin, 1996; Watson, Batchelor, \& Claxton, 1999). A característica básica da abordagem budista é a compreensão da natureza do eu, sendo a compaixão entendida como fundamental na compreensão do ser humano. A compaixão seria, então, na visão budista e oriental, o desejo de todos os seres vivos se libertarem do seu sofrimento (Gillath, Bunge, Shaver, Wendelken, \& Mikulincer, 2005).

A psicologia ocidental conceptualiza a compaixão duma forma mais ampla, como uma combinação de motivos, emoções, pensamentos e comportamentos que nos abre ao sofrimento dos outros e de nós próprios, levando-nos a compreender esse sofrimento duma forma não avaliativa, bem como a actuar tendo em vista o seu alívio (Gilbert, 2005a). Envolve estar aberto ao sofrimento dos outros, o desejo de os ajudar a diminuir o sofrimento, tolerância oferecendo aos outros paciência, bondade e uma atitude não crítica, reconhecendo que todos os seres humanos são imperfeitos e cometem erros. Do mesmo, modo a auto-compaixão implica estar aberto ao próprio sofrimento, experienciando sentimentos de calor, de cuidado e de compreensão para com o eu, numa atitude de observação curiosa e de compreensão não avaliativa em relação ao nossos erros e inadequações e reconhecer as nossas experiências como parte duma experiência humana comum (Neff, 2003a). É por isso que a auto-compaixão se distingue da auto-pena ou comiseração pelo eu (Goldstein \& Kornfield, 1987), na medida em que quando os indivíduos sentem pena de si próprios, experimentam um forte sentimento de desligamento e afastamento dos outros, envolvem-se totalmente nos seus problemas esquecendo que os outros experimentam as mesmas ou piores dificuldades. Esta sobre-identificação com a experiência interna negativa torna difícil o distanciamento da situação e a adopção de uma perspectiva mais objectiva (Bennett-Goleman, 2001). Pelo contrário, a autocompaixão requer uma actividade meta-cognitiva que permita o reconhecimento das experiências interactivas do eu-outros, que quebre o ciclo da sobre-identificação e que aumente o sentimento de ligação e de interconectividade, diminuindo os sentimentos egocêntricos de separação e isolamento. Tende a colocar as experiências pessoais numa perspectiva maior, em que a extensão do sofrimento assume maior clareza. Uma atitude compassiva para com o eu implica uma perspectiva mental equilibrada, ou seja, um estado da mente aberto, receptivo e não avaliativo em que o indivíduo observa os seus pensamentos e sentimentos tal como eles aparecem na corrente da consciência sem tentar modificá-los, eliminá-los ou evitá-los (Hayes, Luoma, Bond, Masuda, \& Lillis, 2006; Teasdale et al., 2000).

\subsection{O que é a Auto-Compaixão?}

Segundo Neff (2003a), a auto-compaixão representa uma atitude calorosa e de aceitação pelos aspectos negativos do self ou da vida, sendo composta por três 
componentes básicos: (a) calor/compreensão, isto é, a capacidade para ser amável e compreensivel para consigo próprio, em vez de ser demasiado crítico e punitivo; (b) condição humana, que significa entender as próprias experiências como parte de uma experiência humana maior; e (c) mindfulness, a consciência equilibrada e aceitação dos próprios sentimentos e sentimentos dolorosos, sem uma excessiva sobre-identificação com os mesmos. Estes componentes são conceptualmente e fenomenologicamente distintos apesar de serem interactivos e interdependentes. Assim, ter uma verdadeira atitude auto-compassiva pressupõe desejar bem-estar ao eu, encorajá-lo a mudar de forma calorosa quando necessário e a rectificar padrões de comportamento disfuncionais e dolorosos (Neff, 2003a).

A auto-compaixão pode ser vista como uma estratégia de regulação emocional extremamente útil, em que os sentimentos e pensamentos negativos não são evitados, mas sim encarados com uma consciência clara, cuidada e compreensiva e com um sentido de partilha comum da experiência. As emoções negativas são transformadas em estados emocionais positivos, permitindo uma apreensão mais clara da situação e a adopção de acções para com o eu ou meio mais apropriadas e eficazes (Folkman \& Moskowitz, 2000; Isen, 2000; Neff, 2003a). Se os indivíduos forem auto-compassivos perante experiências de fracasso ou inadequação conseguem ter uma atitude compreensiva, de calor e tolerância, reconhecendo que ser-se imperfeito e cometer erros faz parte da experiência humana comum, ou seja, alguma coisa que acontece a todos e não apenas "a mim". Ao fazerem isso os indivíduos colocam a experiência humana numa perspectiva mental mais clara e equilibrada em que as emoções negativas não são suprimidas ou evitadas, mas sim aceites como são no momento presente. Esta capacidade de sermos capazes de analisar e encarar a nossa experiência como parte da condição humana protege-nos do egocentrismo excessivo dos nossos problemas e experiências internas, permitindo-nos lidar melhor com o sofrimento e manter o sentimento de ligação e conexão aos outros e a nós próprios. É por esta razão que a auto-compaixão poderá ser um componente importante da inteligência emocional, uma vez que esta envolve a capacidade de monitorização e identificação das emoções e de utilização competente dessa informação para guiar e orientar os nossos pensamentos e comportamentos (Neff, 2003a; Salovey \& Mayer, 1990).

Partindo de uma perspectiva diferente, Gilbert (1989, 2005a, 2005b) define a auto-compaixão com base no legado da psicologia evolucionária e, mais concretamente, da teoria da vinculação e da teoria das mentalidades sociais. Segundo este autor a auto-compaixão deriva da evolução do sistema fisiológico dos mamíferos subjacente à vinculação e ao comportamento de prestação de cuidados. De facto, os mamíferos, e em particular os humanos, são sensíveis aos sinais de cuidado, afecto e sofrimento emitidos pelos outros tendo desen- 
volvido mecanismos específicos de vinculação e ligação aos outros (Gilbert \& Procter, 2006). Quando no mundo social de referência os outros criam na mente um estado de segurança e fornecem calor e validação surge no indivíduo um sentimento de ser amado e desejado, o que o faz procurar os outros e desempenhar estratégias cooperativas e afiliativas que englobam emoções positivas específicas (simpatia, empatia) (Leahy, 2005). Este estado de segurança, ao qual a compaixão está associada, traduz-se numa atitude de calma, tranquilidade e soothing, de maior criatividade na resolução dos problemas, assim como em comportamentos activos de exploração do meio, de afiliação, maior proximidade, interesse e preocupação com os outros (Gilbert, 2005; Gillath et al., 2005). O sistema de afecto positivo associado à compaixão, focado em sentimentos de afiliação, calor e tranquilização é mediado por sistemas cerebrais e fisiológicos específicos (nos quais a oxitocina parece desempenhar um papel relevante), conferindo tranquilidade por nos sentirmos seguros no mundo e connosco próprios. Este sistema está também ligado à emissão de sinais de cuidado e investimento (toque, expressão facial, tom de voz) por parte dos cuidadores, pela partilha de afecto positivo que estimula o gostar e nos faz sentir pessoas merecedoras de amor, e pela compreensão empática e de aceitação das nossas emoções (Gilbert, 2005b).

Pelo exposto, percebe-se que as estratégias de auto-compaixão relacionam-se com o sistema de vinculação e segurança e traduzem-se num estado interno de calma, aceitação, com comportamentos activos de exploração, criatividade, de afiliação e cuidado pelo eu. Estas estratégias ao estarem mais relacionadas com a mentalidade social de prestação de cuidados envolvem o investimento e atenção para com o objecto de cuidado (eu), a supressão da agressão para com o mesmo, a responsividade à sua angústia, a avaliação e a satisfação das suas necessidades, assim como a empatia, simpatia e afecto para com este. Perante isto revela-se, então, importante perceber que experiências precoces de segurança e ameaça contribuem respectivamente para a formação e desenvolvimento de um sistema de afecto positivo de calor e compaixão e/ou de um sistema focado na ameaça e na procura de segurança. A existência de uma relação vinculativa segura com as figuras significativas (pais, pares) desenvolve competências e respostas empáticas e compassivas de ajuda aos outros, uma vez que tais experiências proporcionam uma fonte de segurança (contentamento) e promovem bons modelos de cuidar (Collins \& Feeney, 2000; Kunce \& Shaver, 1994 citado por Gillath et al., 2005). Ou seja, a estimulação durante o processo de maturação do sistema de afiliação/ calor (experiências de validação emocional, de afecto e de confiança por parte das figuras significativas) contribui para a formação de esquemas eu-outro que serão activados e usados, ao longo da vida, não apenas na formação e manutenção de laços de afiliação (conexão aos outros) como também na regulação emocional 
em situações de stress (Baldwin, 2005; Gilbert, 2005a, 2005b). Pelo contrário, a não disponibilidade das figuras de vinculação impede o desenvolvimento de um sentimento de segurança, surgindo outras estratégias de regulação do afecto como o evitamento, a ansiedade, o auto-criticismo e a vergonha (Gilbert, 2005a, 2005b; Gillath et al., 2005). Concretamente, quando os pais (ou outros significativos) são incapazes de gerar segurança, de transmitir confiança e são ameaçadores (humilhação, abuso, negligência, criticismo e vergonha) há uma sub-estimulação do sistema de afecto positivo de procura de calor, compreensão e tranquilização e uma activação do sistema de ameaça-defesa, com a manifestação de comportamentos e emoções de defesa: raiva/luta, ansiedade/fuga, submissão/apaziguamento (Gilbert, 1989). Ou seja, crianças que foram sistematicamente criticadas, subordinadas e ameaçadas ou que não se sentiram cuidadas e seguras, protegidas e amadas apresentam um sistema de defesa-ameaça sobreestimulado, com a activação de afecto negativo e comportamentos defensivos mais facilmente desencadeáveis e de longa duração. Contextos relacionais desta natureza tornam difícil a aprendizagem de capacidades compassivas, tanto na interacção com os outros como na relação do indivíduo consigo mesmo (Gilbert, 2005a). A activação e a continuidade nesta mentalidade focada na ameaça e defesa aumentam a vulnerabilidade para a psicopatologia através do sentimento de derrota, inferioridade, subordinação, rejeição, vergonha, comparação social, perseguição e da activação de comportamentos defensivos. Parece, então, que a auto-compaixão é uma atitude emocionalmente positiva para com o eu, que funciona como factor protector das consequências negativas do auto-criticismo, do isolamento, da vivência de derrota, da comparação social negativa e da ruminação (Blatt, Quinlan, Chevron, McDonald, \& Zuroff, 1982; Gilbert, 2005a, 2005b; Gilbert, Clarke, Kempel, Miles, \& Irons, 2004; Nolen-Hoeksema, 1991).

\subsection{Auto-Compaixão e psicopatologia}

As investigações recentes sugerem que os indivíduos variam no traço de autocompaixão e que a auto-compaixão está fortemente ligada à saúde psicológica constituindo uma estratégia de auto-regulação emocional com um efeito protector no desenvolvimento e manutenção da psicopatologia (Neff, 2003a, 2003b; Neff, Hsieh, \& Dejitterat, 2005). Kristin Neff (2003a, 2003b) é uma das autoras que mais tem investigado a relação entre a auto-compaixão, a psicopatologia e a saúde psicológica. A maioria da investigação existente sobre este constructo utilizou a Escala da Auto-Compaixão (Self-Compassion Scale; SCS; Neff, 2003a), no entanto, outros investigadores iniciaram a aplicação de induções de humor ou de protocolos terapêuticos como uma forma diferente de avaliar o impacto da auto-compaixão no comportamento e funcionamento (Gilbert \& Procter, 2006; Leary, Tate, Adams, Allen, \& Hancock, 2007). 
Os resultados dos estudos levados a cabo por Neff e colaboradores (2003a, 2005, 2007a, 2007b) mostraram uma relação significativa positiva entre a auto-compaixão e a saúde psicológica, mais concretamente com a satisfação com a vida, a ligação social e a inteligência emocional. Em oposição, a auto-compaixão mostrou-se negativamente correlacionada com o auto-criticismo, a depressão, a ansiedade, a ruminação, a supressão do pensamento e o perfeccionismo neurótico (Gilbert \& Procter, 2006; Leary, Tate, Adams, Allen, \& Hancock, 2007).

De referir um desses estudos em que os autores pretenderam estudar as capacidades protectoras da auto-compaixão (em comparação às qualidades da auto-estima) em situações de "ameaça ao eu", geradoras de ansiedade. Os dados obtidos confirmaram a hipótese de que as capacidades da auto-compaixão em situações de ameaça (ansiedade avaliativa) exercem um efeito protector, diferente da auto-estima (Neff et al., 2007a). Neff, Rude e Kirkpatrick (2007b) mostraram também que a auto-compaixão apresenta uma correlação negativa com o traço neuroticismo (como seria de esperar), e uma correlação positiva com os traços de agradabilidade, extroversão e conscienciosidade, avaliados pelo NEO-FFI (Costa \& McCrae, 1992). Os estudos de Leary e colaboradores (2007) sugerem que a autocompaixão é uma estratégia de regulação emocional importante, na medida em que modera as reacções a acontecimentos negativos (fracasso, rejeição, vergonha), amortecendo o impacto destes acontecimentos negativos para o indivíduo. Este efeito amortecedor poderá estar também relacionado com o facto dos indivíduos mais compassivos serem menos auto-críticos, fazerem avaliações mais realistas dos seus desempenhos, terem mais tolerância e compreensão pelo eu e a auto-avaliação não depender tanto da qualidade ou quantidade dos resultados obtidos. Noutro estudo, Neff e colaboradores (2005) procuraram perceber a contribuição da auto-compaixão no contexto académico, e verificaram que a auto-compaixão mostra-se correlacionada, positivamente, com objectivos de mestria, focados na aprendizagem de novas competências, e negativamente com objectivos de desempenho, ligados à valorização pessoal pelo sucesso ou à defesa desse valor pelo evitamento do fracasso. Outro aspecto interessante neste estudo é que a auto-compaixão se revela útil e eficaz no lidar com experiências de fracasso, através do recurso a estratégias mais adaptativas, tais como, a reinterpretação positiva ou a aceitação de que os fracassos e erros são inevitáveis, inerentes à condição humana. O que estes dados sugerem é que a característica nuclear da auto-compaixão é a capacidade de não ajuizamento crítico e punitivo do eu perante situações difíceis e de fracasso, sendo o auto-criticismo um importante preditor da depressão e ansiedade (Blatt, Quinlan, Pilkonis, \& Shea, 1995; Gilbert \& Irons, 2004). Os mesmos resultados são obtidos por Neff e colaboradores (2003a, 2003b, 2007a) em que a auto-compaixão se mostra um robusto preditor negativo dos sintomas depressivos e ansiosos quando se controla o efeito do auto-criticismo 
e afecto negativo. Então, a auto-compaixão não é apenas um "olhar superficial" da experiência interna ou o evitamento de sentimentos negativos, mas o reconhecimento consciente do sofrimento do self, sendo que este reconhecimento permite gerar sentimentos de compreensão, aceitação e interligação com o resto da humanidade. A auto-compaixão permite, assim, a activação do sistema de segurança e soothing, fisiologicamente relacionado com o sistema de vinculação e prestação de cuidados, levando à diminuição das emoções negativas (medo) e dos sentimentos de isolamento (Gilbert \& Irons, 2005). Outro dado interessante parece ser os resultados obtidos com a aplicação do Treino da Mente Compassiva (intervenção terapêutica desenvolvida e dirigida para pessoas auto-críticas com dificuldades em desenvolverem capacidades de auto-aceitação, tranquilização e calor) em que se verifica que os doentes com elevado auto-criticismo apresentam uma redução significativa na sintomatologia depressiva, ansiosa, vergonha e nos comportamentos submissos, assim como um aumento na capacidade de auto-tranquilização e compaixão pelo eu. O Treino da Mente Compassiva não se destina apenas a desafiar ou a reestruturar pensamentos disfuncionais negativos acerca do eu, visando, acima de tudo, a descoberta de novos recursos do self e a criação de novos padrões de organização da mente (Gilbert \& Irons, 2005; Gilbert \& Procter, 2006).

\subsection{Avaliação da Auto-Compaixão}

A Escala de Auto-Compaixão de Neff (SCS, Self-Compassion Scale, Neff, 2003a; tradução e adaptação para a população portuguesa de Castilho, \& Pinto-Gouveia, 2006) tem sido o instrumento de auto-resposta mais utilizado. Esta escala é composta por 26 itens divididos em 6 subescalas: Calor/Compreensão (ex: "Tento ser compreensivo e paciente em relação aos aspectos da minha personalidade e que não gosto"); Auto-Crítica (ex: "Desaprovo-me e faço julgamentos acerca dos meus erros e inadequações"; Humanidade Comum (ex: "Tento ver os meus erros e falhas como parte da condição humana"); Isolamento (ex: "Quando penso acerca das minhas inadequações e defeitos sinto-me mais separado e desligado do resto do mundo"); Mindfulness (ex: "Quando alguma coisa dolorosa acontece tento ter uma visão equilibrada da situação") e Sobre-Identificação (ex: "Quando me sinto em baixo tendo a ficar obcecado com tudo aquilo que está errado"). No estudo das características psicométricas da versão inglesa original da escala (Neff, 2003a) os resultados obtidos indicaram uma elevada inter-correlação entre as seis dimensões teóricas. A análise confirmatória determinou a existência de um único factor de ordem superior a explicar estas inter-correlações, o que sugere a auto-compaixão enquanto traço de segunda ordem, resultante da combinação de diferentes sub-traços (Neff, 2003a). A escala apresenta uma boa consistência interna (.92) e fidelidade temporal (.93). Outra característica analisada foi a vali- 
dade de constructo e os dados obtidos sugerem uma boa validade, na medida em que esta não evidenciou uma correlação significativa com enviezamentos de desejabilidade social. No que concerne à validade de conteúdo os dados mostraram que os indivíduos com níveis mais elevados de auto-compaixão relataram serem igualmente amáveis consigo próprios e com os outros, enquanto que os indivíduos com níveis mais baixos de auto-compaixão descreveram ser mais amáveis com os outros do que consigo próprios. Estes resultados parecem sugerir que a existência de uma atitude de respeito e de cuidado para com o eu (assim como para com o outro) é um componente importante da auto-compaixão. Para estudar a validade convergente da escala da auto-compaixão a autora calculou as suas correlações com outras escalas que avaliam constructos relacionados (auto-criticismo, inteligência emocional, ligação social). As correlações encontradas de magnitude moderada indicam que as escalas medem constructos diferentes (validade divergente) (Neff, 2003a). Este conjunto de dados mostra que a SCS na sua versão original possui boas qualidades psicométricas e validade, e aponta para a sua utilidade na avaliação da auto-compaixão.

Outras escalas (como a Escala de Compaixão e Cuidado pelo Eu (ECCE) e a Escala de Compaixão e Cuidado pelos Outros (ECCO), recentemente construídas por Gilbert (no prelo) estão ainda em desenvolvimento e procuram clarificar melhor os conceitos de auto-compaixão e de compaixão pelo outro. A Escala de Compaixão e Cuidado pelo Eu (ECCE) (CCS, Compassion and Care for Self Scale; Gilbert, 2007) e a Escala de Compaixão e Cuidado pelos Outros (ECCO) (CCS, Compassion and Care for Other Scale; Gilbert, 2007) (tradução e adaptação para a população portuguesa de Dinis, Matos, \& Pinto-Gouveia, 2008) diferem apenas no conteúdo dos itens, e são compostas por 36 itens divididos em 7 subescalas que correspondem a cada um dos componentes da compaixão definidos pelo referido autor.

\subsection{Objectivos}

No presente trabalho, o primeiro estudo, procura analisar as características psicométricas da versão portuguesa da SCS numa amostra de estudantes universitários, para que este instrumento possa ser utilizado em Portugal. No segundo estudo, estudamos que tipo de experiências adversas na infância contribuem para o não desenvolvimento de uma atitude compassiva para com o eu, e a relação entre a autocompaixão, a comparação social e os sintomas depressivos. Mais concretamente, exploramos as experiências parentais negativas mais associadas às dimensões negativas da auto-compaixão (auto-criticismo, isolamento e sobre-identificação) e hipotetizamos que este processo de auto-regulação interna poderá mediar o efeito das experiências negativas na infância sobre os sintomas depressivos. Se assim for, estes dados terão implicações importantes para a prática clínica, sobretudo 
para os indivíduos provenientes de a mbientes parentais hostis, na medida em que aprender a ser auto-compassivo poderá constituir uma estratégia de regulação útil e protectora da sintomatologia depressiva. Por último, pretendemos analisar o contributo da auto-compaixão para a comparação social, particularmente para a aceitação social.

\section{Metodologia}

\subsection{Participantes}

A presente a mostra é constituída por 631 estudantes universitários, 163 indivíduos do género masculino (25.83\%) e 468 do género feminino (74.17\%). A média das idades do total da amostra é de $20.65(D P=2.68)$ e a média dos anos de escolaridade é de $13.83(D P=1.57)$. Quanto ao estado civil existe um predomínio de indivíduos solteiros (98.50\%). Não foram encontradas diferenças estatisticamente significativas entre os dois géneros para a idade $\left(t_{(629)}=.87 ; p \leq .01\right)$, para o estado civil $\left(\chi_{2}=.35 ; p \leq .01\right)$ e anos de escolaridade $\left(t_{(629)}=1.68 ; p \leq .01\right)$.

\subsection{Instrumentos}

Escalas de Ansiedade, Depressão e Stress - EADS-42 (DASS-42; Depression Anxiety Stress Scales, Lovibond \& Lovibond, 1995; Tradução e adaptação de Pais-Ribeiro, Honrado \& Leal, 2004). Esta escala é constituída por 42 itens e pretende avaliar sintomas emocionais negativos correspondentes a 3 dimensões: Depressão, Ansiedade e Stress. A versão portuguesa apresenta uma boa consistência interna, semelhante à versão original, assim como uma boa validade convergente e discriminante. $\mathrm{Na}$ nossa amostra os valores obtidos para a consistência interna foram: subescala Depressão .93, subescala Ansiedade .87 e na subescala Stress .91.

Questionário de Experiências Infantis (CECA.Q; Childhood Experience of Care and Abuse Questionnaire, Bifulco, Bernazzani, Moran, \& Jacobs, 2005; Tradução e adaptação de Carvalho \& Pinto-Gouveia, 2006). Avalia aspectos objectivos das experiências na infância e do comportamento parental. Visa o despiste de experiências de abuso físico e sexual e de medidas de antipatia e de negligência por parte das figuras parentais, focando-se no período anterior aos 17 anos. O estudo levado a cabo por Bifulco e colaboradores (2005) para avaliação das qualidades psicométricas da escala revelou uma boa consistência interna para as escalas de antipatia ( $\alpha=.81$ ) e negligência $(\alpha=.80$ ), assim como uma validade temporal satisfatória. Estes resultados apontam o CECA.O como uma ferramenta útil na 
investigação em amostras clínicas para despiste de indivíduos com experiências de abuso físico, sexual e maus tratos durante a infância. Na amostra do nosso estudo o CECA.Q apresentou uma consistência interna, com valores alpha de Cronbach para a subescala de Antipatia Mãe de .78 e Antipatia Pai .82 e para a subescala de Negligência Mãe de .75 e Negligência Pai .85.

Escala de Comparação Social - ECS (SCS; Social Comparison Scale, Allan \& Gilbert, 1995; Tradução e adaptação de Gato \& Pinto-Gouveia, 2003). Avalia a forma como os indivíduos se comparam no relacionamento com os outros. É composto por 11 constructos bipolares (ex. inferior/superior, inseguro/mais seguro; rejeitado/aceite) em relação aos quais os indivíduos exprimem o modo como se percepcionam em relação a cada um destes constructos. Possui duas sub-escalas: Hierarquia (Rank) e Ajustamento ao Grupo (itens relacionados com a adaptação e a aceitação por parte de um grupo social). Neste estudo a consistência interna obtida para o total da escala foi $\alpha=.87$, para a subescala Hierarquia $\alpha=.80$ e para a subescala de Ajustamento Social foi de $\alpha=.71$.

Questionário de Orientação para a Vida-Revisto (Optimismo) (LOT-R; Life Orientation Questionnaire Test-Revised; Sheier, Carver \& Bridges, 1994; Tradução e adaptação de Carvalho, \& Pinto-Gouveia, 2006). É um questionário de auto-preenchimento, com 10 itens, sendo que destes apenas seis são usados na cotação para a obtenção de um valor de optimismo (resultados mais elevados indicam mais optimismo). Avalia as expectativas generalizadas para resultados positivos e negativos, e tem um formato de resposta tipo Likert que varia entre "o" (discordo completamente) e "4" (estou completamente de acordo). A consistência interna avaliada através do alfa de Cronbach revelou uma fidelidade de .82 (Sheier et al., 1994). Com a amostra do nosso estudo foi obtido um valor de consistência interna de $\alpha=.78$.

Escala de Auto-Compaixão (SCS; Self-Compassion Scale, Neff, 2003a; Tradução e adaptação de Castilho \& Pinto-Gouveia, 2006). Esta escala é um instrumento de medida de auto-resposta com 26 itens organizados em 6 subescalas que avaliam as seguintes dimensões: Calor/compreensão, Auto-Crítica, Condição Humana, Isolamento, Mindfulness e Sobre-identificação. Os resultados obtidos por Neff (2003a) revelaram a existência de níveis de consistência interna ( $\alpha=.92)$ e testereteste $(\alpha=.93)$ muito bons.

\subsection{Procedimento}

A Self-Compassion Scale (SCS) foi traduzida e adaptada para a língua portuguesa seguindo as instruções e normas de De Figueiredo (1980), ou seja, a tradução, a retroversão e a revisão por um tradutor especializado. Administrou-se a bateria de escalas aos alunos da licenciatura em Psicologia (Faculdade de Psicologia e de 
Ciências da Educação da Universidade de Coimbra e Instituto Superior Miguel Torga de Coimbra). Foram igualmente recolhidos alguns dados demográficos e obtido o consentimento informado dos participantes garantindo o anonimato.

\subsection{Procedimentos estatísticos}

$\mathrm{Na}$ análise dos dados recorreu-se ao SPSS versão 15.0. Todos os valores com probabilidade associada inferior a .05 foram considerados estatisticamente significativos.

Procedemos à análise da consistência interna através do cálculo do alfa de Cronbach, considerada a melhor estimativa de fidelidade de um teste (Nunnally, 1978). A qualidade dos itens foi verificada através do cálculo da correlação do item com o total da escala excepto o próprio item (Nunnally, 1978). A fidelidade teste-reteste bem como as validades convergente e divergente foram analisadas através do coeficiente de correlação paramétrico de Pearson (Nunnally, 1978).

Para o segundo estudo fizemos matrizes de correlação de Pearson para investigar as relações entre as variáveis em estudo. Modelos de regressão linear e hierárquica foram usados para testar os efeitos do mediador em cada uma das variáveis dependentes.

\section{Resultados}

\subsection{Propriedades psicométricas da Escala da Auto-Compaixão}

\subsubsection{Análise dos itens e da consistência interna}

As médias, desvios-padrão e correlações item-total para cada item da escala da auto-compaixão são apresentadas na Tabela 1. Como se pode verificar, todos os itens mostram correlações item-total superiores ou iguais .35, excepto o item 7 ("Quando estou em baixo lembro-me que existem muitas outras pessoas no mundo que se sentem como eu"), o item 10 ("Quando me sinto inadequado(a) de alguma forma tento lembrar-me que a maioria das pessoas, por vezes, também sente o mesmo") e o item 22 ("Quando me sinto em baixo tento olhar para os meus sentimentos com curiosidade e abertura") que apresentam correlações item-total de.23, .28 e .30, respectivamente. Embora estes itens não atinjam o critério, previamente estabelecido, de correlação item-total > .30, foram mantidos porque a eliminação destes três itens não aumentava a consistência interna da escala. 
A consistência interna da versão portuguesa da SCS foi avaliada através do cálculo de alfa de Cronbach quer para a totalidade dos itens da escala (26), quer para cada uma das dimensões teóricas que a compõem, revelando uma boa consistência interna: 89 para o Total da escala; para a subescala de Calor/Compreensão .84; para a subescala Auto-crítica .82; para a subescala Condição Humana .77; para a subescala Isolamento .75; para a subescala Mindfulness .73; e finalmente para a subescala Sobre-identificação .78 .

Tabela 1. Médias, desvio padrão, correlações item-total e correlações teste reteste para cada item e dimensão da Escala da Auto-compaixão $(N=631)$

\begin{tabular}{|c|c|c|c|c|}
\hline Itens e respectivo $\mathrm{n}^{\circ}$ & $M$ & $D P$ & $\begin{array}{l}\text { Item- } \\
\text { Total } \\
R\end{array}$ & $\begin{array}{c}\text { Teste- } \\
\text { reteste } \\
\mathrm{R} \\
(n=34)\end{array}$ \\
\hline \multicolumn{5}{|l|}{ Calor/Compreensão $(\alpha=.84)$} \\
\hline $\begin{array}{l}\text { Tento ser carinhoso comigo próprio quando estou a } \\
\text { sofrer emocionalmente (5) }\end{array}$ & 3.00 & .99 & .43 & .50 \\
\hline $\begin{array}{l}\text { Quando atravesso um momento verdadeiramente } \\
\text { difícil na minha vida dou a mim própria a ternura e } \\
\text { afecto que necessito (12) }\end{array}$ & 2.86 & .97 & .46 & .68 \\
\hline $\begin{array}{l}\text { Sou tolerante e afectuoso(a) comigo mesmo(a) } \\
\text { quando experiencio sofrimento (19) }\end{array}$ & 2.93 & .95 & .55 & .45 \\
\hline Sou tolerante com os meus erros e inadequações (23) & 2.90 & .89 & .59 & .43 \\
\hline $\begin{array}{l}\text { Tento ser compreensivo(a) e paciente em relação aos } \\
\text { aspectos da minha personalidade de que não gosto (26) }\end{array}$ & 3.06 & .88 & .50 & .04 \\
\hline \multicolumn{5}{|l|}{ Auto-Crítica $(\alpha=.82)$} \\
\hline $\begin{array}{l}\text { Desaprovo-me e faço julgamentos acerca dos meus } \\
\text { erros e inadequações (1) }\end{array}$ & 3.23 & 1.01 & .42 & .19 \\
\hline $\begin{array}{l}\text { Quando passo por tempos dificeis tendo a ser muito } \\
\text { exigente e duro(a) comigo mesmo(a) (8) }\end{array}$ & 3.46 & .98 & .47 & .50 \\
\hline $\begin{array}{l}\text { Sou intolerante e pouco paciente em relação aos as- } \\
\text { pectos da minha personalidade que não gosto (11) }\end{array}$ & 3.61 & .99 & .53 & .48 \\
\hline $\begin{array}{l}\text { Quando vejo aspectos de mim próprio(a) que não } \\
\text { gosto fico muito muito em baixo (16) }\end{array}$ & 3.55 & .99 & .54 & .48 \\
\hline $\begin{array}{l}\text { Posso ser bastante fria e dura comigo mesmo(a) } \\
\text { quando experiencio sofrimento (21) }\end{array}$ & 3.66 & 1.02 & .53 & .42 \\
\hline \multicolumn{5}{|l|}{ Condição Humana $(\alpha=.77)$} \\
\hline $\begin{array}{l}\text { Quando as coisas me correm mal vejo as dificuldades } \\
\text { como fazendo parte da vida, e pelas quais toda a gente } \\
\text { passa (3) }\end{array}$ & 3.34 & .99 & .36 & .23 \\
\hline $\begin{array}{l}\text { Quando estou em baixo lembro-me que existem muitas } \\
\text { outras pessoas no mundo que se sentem como eu ( } 7)\end{array}$ & 2.94 & 1.03 & .23 & .50 \\
\hline $\begin{array}{l}\text { Quando me sinto inadequado(a) de alguma forma, } \\
\text { tento lembrar-me que a maioria das pessoas, por } \\
\text { vezes, também sente o mesmo (10) }\end{array}$ & 2.90 & .97 & .28 & .12 \\
\hline $\begin{array}{l}\text { Tento ver os meus erros e falhas como parte da con- } \\
\text { dição humana (15) }\end{array}$ & 3.27 & .93 & .53 & .39 \\
\hline Isolamento $(\alpha=.75)$ & & & & \\
\hline
\end{tabular}


Quando penso acerca das minhas inadequações e defeitos sinto-me mais separado e desligado do rest do mundo (4)

Quando me sinto em baixo tenho tendência para achar que a maioria das pessoas é, provavelmente, mais feliz do que eu (13)

$\begin{array}{llll}3.63 & .98 & .47 & .48\end{array}$

Quando me sinto com muitas dificuldades tendo a

pensar que para as outras pessoas as coisas são mais fáceis (18)

Quando falho nalguma coisa importante para mim tendo a sentir-me sozinha no meu fracasso (25)

$\begin{array}{llll}3.27 & 1.01 & .48 & .71 \\ 3.44 & .94 & .42 & .26 \\ 3.29 & 1.00 & .49 & .60\end{array}$

$\begin{array}{llll}3.27 & 1.01 & .48 & .71 \\ 3.44 & .94 & .42 & .26 \\ 3.29 & 1.00 & .49 & .60\end{array}$

$\begin{array}{llll}3.27 & 1.01 & .48 & .71 \\ 3.44 & .94 & .42 & .26 \\ 3.29 & 1.00 & .49 & .60\end{array}$

Mindfulness ( $\alpha=.73$ )

Quando alguma coisa me aborrece ou entristece tento manter o meu equilíbrio emocional (controlo as minhas emoções) (9)

Quando alguma coisa dolorosa acontece tento ter uma visão equilibrada da situação (14)

$\begin{array}{llll}3.27 & 1.01 & .48 & .71 \\ 3.44 & .94 & .42 & .26 \\ 3.29 & 1.00 & .49 & .60\end{array}$

Quando eu falho em alguma coisa importante para mim tento manter as coisas em perspectiva (não dramatizo) (17)

Quando me sinto em baixo tento olhar para os meus sentimentos com curiosidade e abertura (22)

$\begin{array}{llll}3.26 & .94 & .45 & .65 \\ 3.13 & .91 & .52 & .59 \\ 2.98 & .91 & .54 & .39 \\ 2.75 & .89 & .30 & .45\end{array}$

Sobre-identificação ( $\alpha=.78)$

Quando me sinto em baixo tendo a fixar-me e a ficar obcecada com tudo aquilo que está errado (2)

$\begin{array}{llll}3.51 & 1.10 \quad .58 & .45\end{array}$

Quando falho em alguma coisa que é importante para mim martirizo-me com sentimentos de inadequação (6) Quando alguma coisa me aborrece ou entristece deixo-me levar pelos meus sentimentos (20) Quando alguma coisa dolorosa acontece tendo a exagerar a sua importância (24)

$\begin{array}{llll}3.70 & 1.06 & .61 & .36 \\ 3.01 & .93 & .37 & .43 \\ 3.36 & 1.00 & .52 & .51\end{array}$

Total $(\alpha=.89)$

$\begin{array}{llll}84.04 & 13.25 & 1.00 & .78\end{array}$

\subsubsection{Estabilidade temporal}

A SCS foi de novo admnistrada a 34 estudantes do ensino superior após um intervalo de tempo de 4 semanas, obtendo-se um coeficiente de correlação de Pearson .78. Os dados obtidos sugerem uma aceitável estabilidade temporal deste instrumento (cf. Tabela 1).

\subsubsection{Validade convergente e divergente}

A validade convergente desta escala foi avaliada através das suas correlações com a Escala de Comparação Social (ECS) e a Escala de Optimismo (LOT-R). Matrizes de correlação de Pearson foram realizadas entre o Total da SCS e subescalas e as subescalas de Depressão, Ansiedade e Stress, avaliadas pela EADS-42, com o objectivo de analisar a validade divergente (cf. Tabela 2). 
Tabela 2. Matriz de correlações entre o total da SCS e subescalas, o total da ECS e subescalas, o total do LOT-R e a subescala depressão da EADS-42 $(n=631)$

\begin{tabular}{lccccc}
\hline & $\begin{array}{c}\text { ECS } \\
(\text { Total) }\end{array}$ & $\begin{array}{c}\text { Hierarquia } \\
(\text { ECS })\end{array}$ & $\begin{array}{c}\text { Ajustamento } \\
\text { ao Grupo (ECS) }\end{array}$ & LOT-R & $\begin{array}{c}\text { Depressão } \\
(\text { EADS-42) }\end{array}$ \\
\hline Total SCS & $.36^{* *}$ & $.29^{* *}$ & $.77^{* *}$ & $.59^{* *}$ & $-.49^{* *}$ \\
Calor & $.30^{* *}$ & $.24^{* *}$ & $.57^{* *}$ & $.46^{* *}$ & $-.30^{* *}$ \\
Humanidade & $.30^{* *}$ & $.10^{*}$ & $.23^{* *}$ & $.30^{* *}$ & $-.17^{* *}$ \\
Mindfulness & $.21^{* *}$ & $.21^{* *}$ & $.38^{* *}$ & $.48^{* *}$ & $-.25^{* *}$ \\
Auto-crítica & $-.28^{* *}$ & $-.21^{* *}$ & $-.72^{* *}$ & $-.39^{* *}$ & $.38^{* *}$ \\
Isolamento & $-.26^{* *}$ & $-.21^{* *}$ & $-.66^{* *}$ & $-.49^{* *}$ & $.46^{* *}$ \\
Sobre-identificação & $-.29^{* *}$ & $-.22^{* *}$ & $-.58^{* *}$ & $-.44^{* *}$ & $.42^{* *}$ \\
\hline
\end{tabular}

Nota. ${ }^{*} p \leq .05 .{ }^{* *} p \leq .01 . \mathrm{SCS}=$ Escala de Auto-Compaixão; ECS = Escala de Comparação Social; Hierarquia (ECS) = subescala Hierarquia da Escala de Comparação Social; Ajustamento ao Grupo (ECS) = subescala Ajustamento ao Grupo da Escala de Comparação Social; LOT-R = Questionário de Orientação para a Vida-Revisto; Depressão (EADS-42) = subescala Depressão da Escalas de Depressão, Ansiedade e Stress

Relativamente à validade convergente, foram encontrados coeficientes de correlação de magnitude baixa, estatisticamente significativos, entre o total da SCS e o total da ECS $(r=.36 ; p \leq .01)$ e de magnitude elevada entre o total da SCS e a subescala ajustamento ao grupo da ECS $(r=.77 ; p \leq .01)$. Da análise da Tabela 2 destacamos ainda a correlação negativa significativa entre a subescala calor da SCS e a subescala ajustamento ao grupo da ECS ( $r=.57 ; p \leq .01)$ e as correlações negativas, moderadas a elevadas, com as dimensões negativas da auto-compaixão, subescala auto-crítica $(r=-.72 ; p \leq .01)$, subescala isolamento $(r=-.66 ; p \leq .01)$ e subescala sobre-identificação $(r=-.58 ; p \leq$ .01), respectivamente. No que concerne à escala de optimismo foram encontrados valores de correlação significativos positivos moderados com o total da SCS ( $r=.59$; $p \leq .01)$ e com as subescalas calor $(r=.46 ; p \leq .01)$ e mindfulness $(r=.48 ; p \leq .01)$, e baixos com a subescala humanidade comum ( $r=.30 ; p \leq .01)$, como seria de esperar.

Quanto à validade divergente o total da SCS apresentou valores de correlação negativos moderados, mas significativos com a depressão $(r=-.49 ; p \leq .01)$. As correlações obtidas entre as dimensões negativas da SCS e a subescala depressão da EADS-42 são positivas significativas, baixas a moderadas, subescala auto-crítica $(r=.38 ; p \leq .01)$, subescala isolamento $(r=.46 ; p \leq .01)$ e subescala sobre-identificação $(r=.42 ; p \leq .01)$, respectivamente.

\subsection{Relação entre a auto-compaixão, as experiências adversas na infância, a comparação social e a psicopatologia}

No sentido de verificarmos a existência de diferenças significativas entre os sujeitos do géneros masculino e feminino em relação às médias obtidas nas variáveis em estudo, procedemos à realização de testes t-Student. Na Tabela 3 são apresentadas as médias, desvios-padrão das varíaveis em estudo, para cada género, assim como os valores de te de $p$. 
Tabela 3. Médias e Desvios-Padrão das Variáveis Primárias $(N=631)$

\begin{tabular}{|c|c|c|c|c|c|c|c|}
\hline & \multicolumn{2}{|c|}{$\begin{array}{c}\text { Masculino } \\
(n=163)\end{array}$} & \multicolumn{2}{|c|}{$\begin{array}{l}\text { Feminino } \\
(n=468)\end{array}$} & \multirow[b]{2}{*}{$t$} & \multirow[b]{2}{*}{$d f$} & \multirow[b]{2}{*}{$p$} \\
\hline & $M$ & $D P$ & $M$ & $D P$ & & & \\
\hline \multicolumn{8}{|l|}{ Auto-Compaixão } \\
\hline Total SCS & $3 \cdot 34$ & .452 & 3.20 & .521 & 3.17 & 269 & .002 \\
\hline Calor (SCS) & 2.93 & .731 & 2.96 & .726 & -.46 & 269 & .649 \\
\hline Auto-crítica (SCS) & 11.46 & 3.66 & 12.85 & 3.78 & 4.07 & 269 & .000 \\
\hline Humanidade Comum (SCS) & 3.05 & .791 & 3.14 & .746 & -1.32 & 269 & .186 \\
\hline Isolamento (SCS) & $9 \cdot 73$ & 3.11 & 10.59 & 2.89 & 3.22 & 269 & .001 \\
\hline Mindfulness (SCS) & 3.13 & .634 & 2.99 & .686 & 2.27 & 269 & .024 \\
\hline Sobre-identificação (SCS) & $9 \cdot 35$ & 3.03 & 10.80 & 3.13 & 5.13 & 269 & .000 \\
\hline \multicolumn{8}{|l|}{ Exp. Adversas Infância } \\
\hline Antipatia Mãe (CECA.Ǫ) & 14.53 & 4.50 & $14 \cdot 52$ & 4.35 & .01 & 344 & .994 \\
\hline Antipatia Pai (CECA.Ō) & 18.16 & 4.40 & $17 \cdot 52$ & 3.99 & 1.31 & 342 & .193 \\
\hline Negligência Mãe (CECA.Qِ) & 13.39 & 4.62 & 12.18 & 3.64 & 2.78 & 400 & .006 \\
\hline Negligência Pai (CECA.Ō) & 17.23 & 6.14 & 16.37 & 5.56 & 1.37 & 395 & .171 \\
\hline \multicolumn{8}{|l|}{ Comparação social } \\
\hline Total ECS & 69.37 & 12.85 & 70.98 & 12.49 & -1.39 & 615 & .164 \\
\hline Hierarquia (ECS) & 18.14 & 3.25 & 18.09 & 3.37 & .15 & 616 & .885 \\
\hline Ajustamento ao Grupo (ECS) & 10.25 & 1.82 & 10.23 & 2.11 & .07 & 629 & .946 \\
\hline \multicolumn{8}{|l|}{ Psicopatologia } \\
\hline Depressão (EADS-42) & 5.96 & 6.38 & 5.79 & 6.75 & .28 & 602 & .783 \\
\hline
\end{tabular}

Nota. SCS = Escala de Auto-Compaixão; CECA.Q = Questionário de Experiências Infantis; ECS = Escala de Comparação Social; EADS-42 = Escalas de Depressão, Ansiedade e Stress.

Os dados obtidos permitem-nos apontar diferenças entre os géneros ao nível do valor total da SCS $\left(t_{(629)}=3.17 ; p=.002\right)$ e da subescala mindfulness $\left(t_{(629)}=2.27 ; p=.024\right)$ com o género masculino a registar pontuações médias mais elevadas, nas referidas variáveis $(M=3.34 ; D P=.45$ e $M=3.13 ; D P=.63)$. Os dois géneros diferenciam-se ainda nas subescalas auto-crítica $\left(t_{(629)}=4.07 ; p=.000\right)$, isolamento $\left(t_{(629)}=3.218 ; p=\right.$ .001) e sobre-identificação $\left(t_{(629)}=5.13 ; p=.000\right)$, com o género feminino a pontuar significativamente mais alto $(M=12.85 ; D P=3.78 ; M=10.59 ; D P=2.89 ; M=10.80$; $D P=3.13$, respectivamente). Nas subescalas do CECA.Q existem diferenças entre os géneros apenas na subescala negligência mãe $\left(t_{(400)}=2.78 ; p=.006\right)$, com o género masculino a apresentar valores médios mais elevados $(M=13.39 ; D P=4.62)$.

Como os dois géneros diferem significativamente nas subescalas acima apontadas optámos por, nos estudos seguintes, fazer análises separadas para cada um dos géneros.

\subsection{Experiências Adversas na Infância e Auto-Compaixão}

Pretendemos analisar a relação entre a auto-compaixão e as experiências adversas na infância (cf. Tabelas 4 e 5). 
Tabela 4. Correlações entre as experiências adversas na infância e a auto-compaixão, no género masculino $(n=163)$

\begin{tabular}{|c|c|c|c|c|c|c|c|}
\hline & $\frac{\overline{0}}{\text { 어 }}$ & 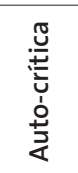 & 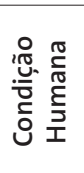 & 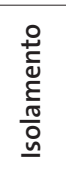 & 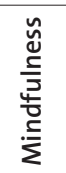 & 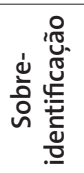 & 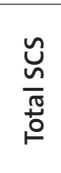 \\
\hline Antipatia Mãe (CECA.O-) & -.01 & .08 & -.03 & .12 & -.08 & .04 & -.08 \\
\hline Antipatia Pai (CECA.O) & .11 & $.29^{* *}$ & .00 & $.32^{* *}$ & -.07 & $.22^{*}$ & $-.23^{*}$ \\
\hline Negligência Mãe (CECA.O-) & -.09 & .05 & -.05 & -.01 & -.14 & .01 & -.09 \\
\hline Negligência Pai (CECA.Oی) & -.06 & $.24^{* *}$ & .00 & $.19^{*}$ & -.05 & $.20^{*}$ & $-.20^{*}$ \\
\hline
\end{tabular}

Nota ${ }^{*} \mathrm{p} \leq .05 ;{ }^{* *} \mathrm{p} \leq .01$. SCS = Escala de Auto-Compaixão; CECA.Q = Questionário de Experiências Infantis.

Como podemos ver na Tabela 4, nos homens, o total da auto-compaixão e as subescalas auto-crítica, isolamento e sobre-identificação mostraram magnitudes de correlação muito baixas a baixas com a subescala antipatia pai $(r=-.23 ; p \leq$ $.05 ; r=.29 ; p \leq .01 ; r=.32 ; p \leq .01 ; r=.22 ; p \leq .01)$ e negligência pai $(r=-.20 ; p \leq .05$; $r=.24 ; p \leq .01 ; r=.19 ; p \leq .05 ; r=.20 ; p \leq .05)$.

Tabela 5. Correlações entre as experiências adversas na infância e a auto-compaixão, no género feminino $(n=468)$

\begin{tabular}{|c|c|c|c|c|c|c|c|}
\hline & $\frac{\bar{\partial}}{\mathrm{N}}$ & 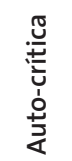 & 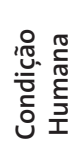 & 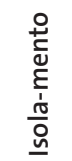 & 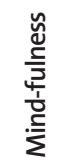 & 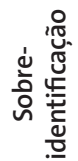 & $\begin{array}{l}\frac{\tilde{n}}{\pi} \\
\frac{\tilde{n}}{0}\end{array}$ \\
\hline Antipatia Mãe (CECA.OQ) & $-.23^{* *}$ & $.24^{* *}$ & -.10 & $.24^{* *}$ & -.09 & $.22^{* *}$ & $-.27^{* *}$ \\
\hline Antipatia Pai (CECA.O) & $-.23^{* *}$ & $.26^{* *}$ & -.07 & $.20^{* *}$ & $-.15^{*}$ & $.18^{* *}$ & $-.26^{* *}$ \\
\hline Negligência Mãe (CECA.OQ) & $-.18^{* *}$ & .06 & $-.15^{*}$ & .10 & -.08 & .08 & $-.15^{* *}$ \\
\hline Negligência Pai (CECA.O-) & $-.19^{* *}$ & $.20^{* *}$ & -.02 & $.19^{* *}$ & -.11 & $.16^{* *}$ & $-.21^{* *}$ \\
\hline
\end{tabular}

Nota. ${ }^{*} p \leq .05 ;{ }^{* *} p \leq .01 . \mathrm{SCS}=$ Escala de Auto-Compaixão; CECA.Q = Questionário de Experiências Infantis.

Pela análise da Tabela 5 constatamos que, nas mulheres, o total da SCS e as subescalas calor, auto-crítica, isolamento e sobre-identificação mostraram correlações muito baixas a baixas com a antipatia mãe $(r=-.27 ; p \leq .01 ; r=-.23 ; p \leq .01 ; r=$ $.24 ; p \leq .01 ; r=.24 ; p \leq .01 ; r=.22 ; p \leq .01)$, com a antipatia pai $(r=-.26 ; p \leq .01 ; r$ $=-.23 ; p \leq .01 ; r=-.15 ; p \leq .05 ; r=.26 ; p \leq .01 ; r=.20 ; p \leq .01 ; r=.18 ; p \leq .01)$, com a negligência mãe $(r=-.15 ; p \leq .05 ; r=-.18 ; p \leq .01)$ e com a negligência pai $(r=-.21$; $p \leq .05 ; r=-.19 ; p \leq .01 ; r=.20 ; p \leq .01 ; r=.19 ; p \leq .01 ; r=.16 ; p \leq .01)$.

No sentido de percebermos melhor estes resultados realizámos análises de regressão linear simples, para o género masculino e género feminino, usando as subescalas do CECA.Q como preditoras da auto-compaixão. Os resultados permitiram verificar que nenhuma das subescalas do CECA.Q constitui um 
preditor significativo da auto-compaixão, nos homens $\left(R^{2}=.01 ; F_{(4,98)}=1.36 ; p\right.$ $=.254)$. No que diz respeito às mulheres verificamos que no seu conjunto as subescalas do CECA.Q explicam $11.5 \%$ da variância da auto-compaixão $\left(R^{2}=\right.$ $\left..100 ; F_{(4,234)}=7.59 ; p \leq .001\right)$, sendo a subescala antipatia mãe a única preditora significativa $(\beta=-.231 ; p=.006)$.

\begin{tabular}{lccc}
\hline & Hierarquia & Ajustamento Grupo & Total ECS \\
\hline Antipatia Mãe (CECA.O) & -.17 & -.14 & $-.19^{*}$ \\
Antipatia Pai (CECA.O_) & -.07 & $-.26^{* *}$ & -.03 \\
Negligência Mãe (CECA.O) & $-.30^{* *}$ & -.13 & $-.34^{* *}$ \\
Negligência Pai (CECA.O_) & -.10 & $-.18^{*}$ & -.13 \\
\hline
\end{tabular}

Nota. ${ }^{*} p \leq .05 ;{ }^{* *} p \leq .01$. ECS = Escala de Comparação Social; CECA.Q = Questionário de Experiências Infantis.

Pela análise da Tabela 6 verificamos que, nos homens, o total da ECS e as subescalas hierarquia e ajustamento ao grupo mostraram valores de correlação significativos muito baixos a baixos com as subescalas antipatia mãe $(r=-.19 ; p \leq .05)$, antipatia pai $(r=-.26 ; p \leq .01)$, negligência mãe $(r=-.34 ; p \leq .01 ; r=-.30 ; p \leq .01)$ e negligência pai $(r=-.18 ; p \leq .05 ; r=-.10 ; p \leq .05)$.

Tabela 7. Correlações entre as subescalas do CECA.Q, no género feminino $(n=468)$

\begin{tabular}{lccc}
\hline & Hierarquia & Ajustamento Grupo & Total ECS \\
\hline Antipatia Mãe (CECA.O) & -.12 & $-.30^{* *}$ & $-.17^{* *}$ \\
Antipatia Pai (CECA.O) & $-.17^{* *}$ & $-.28^{* *}$ & $-.18^{* *}$ \\
Negligência Mãe (CECA.O) & -.09 & $-.15^{*}$ & $-.17^{* *}$ \\
Negligência Pai (CECA.O_) & -.08 & $-.27^{* *}$ & $-.17^{* *}$ \\
\hline
\end{tabular}

Nota. ${ }^{*} p \leq .05 ;{ }^{* *} p \leq .01$. ECS = Escala de Comparação Social; CECA.Q = Questionário de Experiências Infantis.

A análise dos coeficientes de correlação (cf. Tabela 7) permitiu-nos verificar que, nas mulheres, o total da ECS e as suas subescalas apresentaram correlações significativas muito baixas a baixas com as subescalas do CECA.Q, em que destacamos os valores de correlação obtidos com a subescala ajustamento ao grupo, particularmente com a subescala antipatia mãe e antipatia pai $(r=-.30 ; p \leq .01 \mathrm{e}$ $r=-.28 ; p \leq 01$, respectivamente).

De forma a compreender melhor a relação entre as subescalas do CECA.Q e a comparação social realizámos uma análise de regressão linear para testarmos o 
efeito independente das subescalas do CECA.O sobre o ajustamento ao grupo, nos géneros masculino e feminino. Os resultados indicam que o modelo de regressão não é significativo, ou seja, nenhuma das subescalas do CECA.OQ é preditor significativo do ajustamento ao grupo, nos homens. Para o género feminino os dados obtidos mostraram que a subescala antipatia mãe explica $15,3 \%$ da variância do ajustamento ao grupo $\left(R^{2}=.14 ; F_{(4,234)}=10.60 ; p \leq .001\right)$ sendo a única preditora significativa $(\beta=-.303 ; p \leq .001)$.

\subsection{Auto-compaixão e Comparação Social}

De seguida procedeu-se ao estudo da relação entre a auto-compaixão e a comparação social. Para o efeito realizámos correlações de Pearson (cf. Tabelas 8 e 9).

Tabela 8. Correlação entre a Auto-compaixão e a Comparação Social, no género masculino $(n=163)$

\begin{tabular}{|c|c|c|c|c|c|c|c|}
\hline & 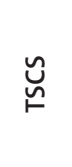 & $\frac{\bar{\partial}}{\stackrel{\widetilde{J}}{U}}$ & $\begin{array}{l}\frac{\pi}{\pi} \\
\frac{\pi}{\pi} \\
\frac{0}{\pi} \\
\frac{\pi}{\pi} \\
\frac{\xi}{3} \\
\frac{1}{1}\end{array}$ & 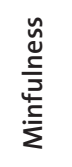 & 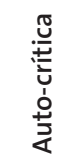 & 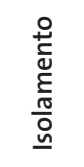 & 悹 \\
\hline TECS & $.37^{* *}$ & .27 & .07 & .12 & $-.27^{*}$ & $-.28^{* *}$ & $-.36^{* *}$ \\
\hline Hierarquia & $.29^{* *}$ & .15 & .03 & $.17^{*}$ & $-.20^{* *}$ & $-.23^{* *}$ & $-.28^{* *}$ \\
\hline Ajustamento ao grupo & $.71^{* *}$ & .37 & .14 & $.20^{* *}$ & $-.65^{* *}$ & $-.64^{* *}$ & $-.58^{* *}$ \\
\hline
\end{tabular}

Nota. ${ }^{*} p \leq .05 ;{ }^{* * *} p \leq .01$. TSCS = Total da Escala de Auto-Compaixão; TECS = Total da Escala de Comparação Social.

Tabela 9. Correlação entre Auto-compaixão e a Comparação Social, no género feminino ( $n=468)$

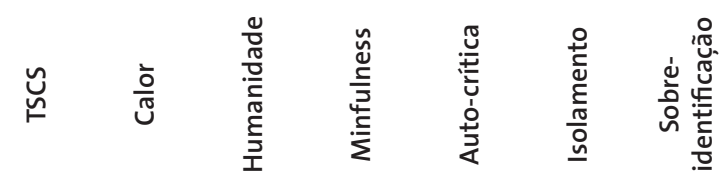

\begin{tabular}{llllllll}
\hline TECS & $.37^{* *}$ & $.31^{* *}$ & $.17^{* *}$ & $.25^{* *}$ & $-.30^{*}$ & $-.26^{* *}$ & $-.28^{* *}$ \\
Hierarquia & $.29^{* *}$ & $.27^{* *}$ & $.12^{* *}$ & $.23^{*}$ & $-.21^{* *}$ & $-.21^{* *}$ & $-.20^{* *}$ \\
Ajustamento ao grupo & $.79^{* *}$ & $.64^{* *}$ & $.26^{* *}$ & $.43^{* *}$ & $-.75^{* *}$ & $-.67^{* *}$ & $-.60^{* *}$ \\
\hline
\end{tabular}

Nota. ${ }^{*} p \leq .05 ;{ }^{* *} p \leq .01$. TSCS = Total da Escala de Auto-Compaixão; TECS = Total da Escala de Comparação Social.

Pela análise das Tabelas 8 e 9 verificamos, nos homens, coeficientes de correlação elevados entre o total da SCS e a subescala ajustamento ao grupo $(r=.71 ; p \leq .01)$, sendo que o mesmo padrão se repete para as mulheres $(r=.79 ; p \leq .01)$. Destacamos ainda, nas mulheres, a correlação positiva significativa entre a subescala calor da SCS e a subescala ajustamento ao grupo $(r=.64 ; p \leq .01)$. 
No sentido de percebermos melhor os resultados obtidos nos homens fizemos uma análise de regressão linear para percebermos o efeito independente da autocompaixão sobre o ajustamento ao grupo, uma vez que é esta subescala da ECS que apresenta correlações mais elevadas com a auto-compaixão. Os resultados mostram que, para o género masculino, o total da SCS explica $50.1 \%$ da variância do ajustamento ao grupo $\left(F_{(4,98)}=161.65, p \leq .001 ; R^{2}=.49\right)$. Estes resultados parecem sugerir que a auto-compaixão é especialmente importante no ajustamento ao grupo. Como nas mulheres se verifica este efeito da subescala antipatia mãe sobre o ajustamento ao grupo fomos tentar perceber se a auto-compaixão medeia o efeito das experiências adversas na infância, avaliadas pelo CECA.O, sobre o ajustamento ao grupo. Para isso realizámos uma análise de regressão hierárquica ou por blocos. Os resultados mostram que as variáveis produzem um modelo significativo na predição do ajustamento ao grupo $\left(F_{(4,234)}=10.60\right.$, $\left.p \leq .000 ; R^{2}=.14\right)$, em que a subescala antipatia mãe explica $15.3 \%$ da variância do ajustamento ao grupo. Quando na equação entra a auto-compaixão, a variância explicada do ajustamento ao grupo passa para $66.2 \%$ verificando-se que quer a antipatia mãe, quer a auto-compaixão têm um efeito independente na variância do ajustamento ao grupo.

\subsection{Experiências adversas na infância, auto-compaixão e depressão}

Neste estudo pretendemos avaliar a relação entre as experiências adversas na infância, a auto-compaixão e os sintomas depressivos, avaliados pela EADS-42. Nos homens, o total da SCS e as subescalas auto-crítica, isolamento e sobreidentificação apresentam correlações negativas significativas de magnitude moderada com a subescala depressão $(r=-.48 ; p \leq .01 ; r=-.43 ; p \leq .01 ; r=-.46$; $p \leq .01 ; r=-.49 ; p \leq .01$, respectivamente). As subescalas do CECA-O não se mostram correlacionadas com a depressão. O mesmo se verifica nas mulheres, em que o total da SCS e as subescalas auto-crítica, isolamento e sobre-identificação apresentam coeficientes de correlação negativos e moderados com a subescala depressão $(r=-.50 ; p \leq .01 ; r=-.37 ; p \leq .01 ; r=-.47 ; p \leq .01 ; r=-.42 ; p \leq .01$, respectivamente). As subescalas antipatia mãe e antipatia pai apresentam correlações positivas significativas de magnitude baixa com a subescala depressão $(r=.32$; $p \leq .01 ; r=.305 ; p \leq .01)$.

Para compreendermos melhor a contribuição da auto-compaixão para os sintomas depressivos fizemos análises de regressão simples utilizando o total da SCS como variável independente ou preditora e a depressão como variável dependente ou critério. Os resultados mostram que no seu conjunto a auto-compaixão explica $28.1 \%$ da variância única da depressão, sendo a subescala sobre-identificação a principal preditora $(\beta=.280 ; p=.027$ ), no género masculino. Nas mulheres veri- 
ficamos que no seu conjunto a auto-compaixão explica $28.5 \%$ da variância da depressão, em que a subescala isolamento se revela o melhor preditor global ( $\beta$ $=.321 ; p=.000)$, seguido da subescala calor $(\beta=-.201 ; p=.001)$ e da subescala sobre-identificação $(\beta=.136 ; p=.037)$.

Finalmente, e no sentido de perceber se a auto-compaixão medeia o efeito das experiências adversas na infância sobre os sintomas depressivos realizámos novamente uma análise de regressão hierárquica. Os resultados mostram que, nas mulheres, as subescalas do CECA.Q traduzidas nas subescalas antipatia mãe e antipatia pai, explicam $15.6 \%$ da variância na depressão no modelo 1. Mas, quando entra na equação a auto-compaixão, a variância explicada da depressão passa para $33.4 \%$, verificando-se que a auto-compaixão constitui o melhor preditor global $(\beta=-.452 ; p<.000)$ seguido da subescala antipatia pai $(\beta=.212 ; p$ $=.007)$ e da subescala antipatia mãe $(\beta=.169 ; p=.024)$. Os resultados obtidos mostram que as experiências adversas na infância e a auto-compaixão têm um efeito independente na predição dos sintomas depressivos.

\section{Discussão}

A compaixão, enquanto processo libertador do sofrimento, tem sido alvo de um marcado e progressivo interesse na comunidade científica ocidental, quer na investigação, quer na prática clínica. Tem-se procurado perceber o conceito, o que contribui para o seu desenvolvimento e o modo como está relacionado com a psicopatologia, a qualidade de vida e com o funcionamento psicológico adaptativo.

Na visão de Kristin Neff (2003a, 2003b) a auto-compaixão assenta em constructos bipolares relacionados com a bondade, humanidade comum e mindfulness que se influenciam e inter-relacionam mutuamente. Embora só recentemente a auto-compaixão tenha sido definida e avaliada revela-se um constructo promissor, tendo sido encontradas associações positivas com vários marcadores de bem-estar, tais como a auto-aceitação, satisfação com vida, ligação aos outros, auto-estima, mindfulness, autonomia, estabelecimento de objectivos de vida, sabedoria reflexiva e afectiva, curiosidade e exploração, felicidade e optimismo (Neff, 2003b). Por outro lado, os resultados obtidos mostraram associações significativas negativas com a ansiedade, depressão, auto-criticismo, neuroticismo, ruminação, supressão do pensamento e perfeccionismo (Neff 2003a, 2003b; Neff et al., 2005). A SCS, através dos diversos estudos levados a cabo por Neff (2003a, 2003 b) tem revelado ser uma escala com boas características psicométricas e útil na avaliação da auto-compaixão. 
Este trabalho teve como objectivo contribuir para o estudo das características psicométricas da versão portuguesa da Escala da Auto-Compaixão (SCS), numa amostra de estudantes do ensino superior da Universidade de Coimbra.

A versão portuguesa da SCS apresenta valores elevados de consistência interna para o total e valores razoáveis para as subescalas, o que indica a boa fidedignidade deste instrumento de medida. A estabilidade temporal foi avaliada num intervalo de 4 semanas e revelou-se aceitável. A validade convergente da escala foi obtida através da inclusão de outras escalas que medem constructos relacionados, como a Escala de Comparação Social e a Escala de Optimismo. Os resultados revelaram correlações moderadas a elevadas com o total da ECS e do LOT-R e com a subescala ajustamento ao grupo. Ao nivel da validade divergente as correlações foram moderadas com os sintomas depressivos, de ansiedade e de stress avaliados pela EADS-42, o que revela que as escalas medem constructos diferentes. De um modo geral, os dados obtidos sugerem que a SCS tem uma validade convergente e divergente satisfatória, como seria de esperar.

Apesar deste estudo apresentar bons resultados psicométricos para a SCS podemos apontar algumas limitações. Uma das limitações prende-se com a representatividade da amostra, sendo que seria útil replicar o estudo numa amostra maior e mais diversificada, com idades e estatutos socioeconómicos diferentes. Outra limitação relaciona-se com a utilização exclusiva de um instrumento de auto-resposta para a avaliação da auto-compaixão, o que pressupõe a necessidade de mais estudos que suportem a validade da escala através do recurso a outras metodologias de avaliação. Será também pertinente investigar a validade discriminante da SCS para garantir a sua aplicabilidade e importância clínica.

No segundo estudo, a nossa primeira previsão era de que experiências negativas na infância, traduzidas por comportamentos parentais de crítica, controlo e desinteresse, estariam associadas a um estilo auto-crítico e a emoções negativas (ansiedade, tristeza, raiva) e, portanto, a uma baixa auto-compaixão. Verificamos que nos homens a existência de um pai crítico, hostil, rejeitador e desinteressado está associado a uma atitude mais crítica e punitiva do eu e, portanto, menos compassiva. Os resultados da análise de regressão sugerem que, nas mulheres, uma mãe controladora, fria e crítica contribui para o desenvolvimento do auto-criticismo e da vergonha. Os resultados obtidos corroboram os estudos existentes que demonstram que são os comportamentos parentais vinculativos e securizantes que contribuem para o desenvolvimento da auto-compaixão. Num estudo recente, Neff e McGehee (in press) descobriram que o suporte materno, o funcionamento familiar harmonioso e a vinculação segura predizem em conjunto níveis elevados de auto-compaixão nas crianças. No mesmo sentido, Gilbert afirma que o investimento parental e o alargamento da prestação de cuidados 
por parte de outros indivíduos proporcionam uma nova maturação fisiológica e cerebral facilitadora do desenvolvimento de novas competências sociais importantes para o envolvimento compassivo numa variedade de relações (com o eu e com os outros), tornando deste modo a vinculação num sistema de regulação e protecção da ameaça (Bowlby, 1973; Gilbert, 2005a, 2005b; Gilbert et al., 2007). De seguida, verificamos que nas mulheres a antipatia mãe prediz o ajustamento e aceitação social, ou seja, a existência de uma mãe crítica e hostil contribui para dificuldades na ligação e aceitação social. Tentámos também perceber a contribuição relativa da auto-compaixão para o ajustamento ao grupo e os resultados obtidos mostraram que nos homens a existência de uma atitude e relação compassiva com o eu é especialmente importante para a aceitação social. Por sua vez, nas mulheres o que parece ser importante para o ajustamento ao grupo é não só ter uma mãe calorosa, cuidadora e reforçadora, mas principalmente ter uma relação compassiva e de aceitação com o eu. Estes dados estão de acordo com a literatura existente, em que os indivíduos provenientes de ambientes calorosos, seguros, de amor e cuidado a prendem e acedem com mais facilidade a esquemas dos outros como compreensivos, empáticos e prestativos, adoptando assim estas competências na auto-regulação interna (Gilbert \& Irons, 2005; Kostner, Zuroff, \& Powers, 1991; Shahar, Blatt, Zuroff, Kupermine \& Leadbeater, 2004). Pelo contrário, os indivíduos provenientes de ambientes invalidantes, hostis e críticos têm uma maior propensão para a vergonha, auto-criticismo e auto-ataque, uma marcada comparação social negativa e relações afiliativas pobres (Gilbert \& Irons, 2004, 2005; Zuroff, Koestner \& Powers, 1994; Irons, Gilbert, Baldwin, Baccus, \& Palmes, 2006). Isto significa que os indivíduos auto-críticos têm marcadas dificuldades na auto-tranquilização e soothing, em parte devido à inexistência de memórias emocionais internalizadas dos outros como calorosos e cuidadores (Gilbert \& Irons, 2005). A não disponibilidade das figuras de vinculação impede o desenvolvimento de um sentimento de segurança, surgindo outras estratégias de regulação do afecto (evitamento, ansiedade, vergonha). A auto-compaixão está, assim, mais relacionada com a vinculação e envolve o investimento e atenção para com o objecto de cuidado, a supressão da agressão para com o mesmo, a responsividade à sua angústia, a avaliação e a satisfação das suas necessidades, assim como a empatia, simpatia e afecto para com este.

Finalmente, na nossa terceira hipótese pretendemos testar, não só que tipo de experiências adversas na infância mais contribuem para os sintomas depressivos, mas se a auto-compaixão medeia o efeito das experiências negativas sobre a sintomatologia depressiva. Verificamos que nos homens a identificação em demasia com os próprios pensamentos e emoções negativas, em vez de ser capaz de tomar uma atitude equilibrada de aceitação para com os mesmos, parece que contribui para os sintomas depressivos. Por sua vez nas mulheres, os dados 
sugerem que encarar as próprias experiências e fracassos como algo isolado do resto do mundo, a ausência de uma atitude calorosa e de tranquilização para com o eu e a sobre-identificação com os pensamentos e sentimentos negativos predizem os sintomas depressivos. Estes dados confirmam os resultados obtidos noutros estudos, em que a auto-compaixão se revela um componente importante e protector da sintomatologia depressiva ou da sua recaída (Neff, 2005; Neff \& Vonk, 2009; Gilbert \& Irons, 2004, 2005). Por último, os resultados da análise de regressão hierárquica, nas mulheres, mostraram que a hostilidade, frieza e criticismo parental e uma auto-compaixão baixa (elevado auto-criticismo) especificamente contribuem para a sintomatologia depressiva.

Em síntese, a capacidade para sermos amáveis connosco próprios e a atitude equilibrada de curiosidade e de aceitação dos próprios pensamentos e sentimentos dolorosos é, de facto, um indicador de saúde mental. Os dados obtidos neste estudo são de enorme relevância, na medida em que apontam para a necessidade de englobar nos protocolos terapêuticos a aprendizagem e o desenvolvimento de estratégias de auto-regulação emocional focadas no sistema de afecto positivo ligado à vinculação, kindness e soothing, criando uma nova organização no estado da mente fundamental para lidar com perdas, fracassos e ameaças sociais (Gilbert, 2005a, 2005b; Gilbert \& Procter, 2006). As limitações existentes neste estudo prendem-se, por um lado, com o número mais expressivo de estudantes do género feminino o que questiona a representatividade dos resultados, sendo necessária a sua replicação noutras amostras (população clínica, por exemplo). Por outro lado, seria interessante melhorar estes resultados com outras variáveis intrinsecamente relacionadas, como a vergonha externa e interna. Contudo, os resultados apontam para a importância do desenvolvimento da auto-compaixão como uma abordagem terapêutica para os indivíduos com experiências desenvolvimentais de rejeição, auto-críticos e com marcadas dificuldades na afiliação e aceitação social.

\section{Referências Bibliográficas}

Allan, S., \& Gilbert, P. (1995). A social comparison scale: Psychometric properties and relationship to psychopathology. Personality and Individual Differences, 3, 293-299. doi:10.1016/01918869(95)00086-L

American Psychiatric Association. (1980). Diagnostic and statistical manual of mental disorders (3rd ed.). Washington, DC: American Psychiatric Association.

American Psychiatric Association. (2002). Manual de Diagnóstico e Estatística das Perturbações Mentais (4th ed., Texto Revisto). Lisboa: Climepsi Editores.

Baldwin, M.W. (1992). Relational schemas and the processing of social information. Psychological Bulletin, 112, 461-84.

Baldwin, M. W. (2005). Interpersonal Cognition. New York: Guilford Press. 
Baldwin, M. W. \& Dandeneau, S. D. (2005). Understanding and modifying the relational schemas underlying insecurity. In M.W. Baldwin (Ed.), Interpersonal Cognition (pp. 33-61). Bennett-Goleman, T. (2001). Emotional alchemy: How the mind can heal the heart. New York: Three Rivers Press.

Bifulco, A., Bernazzani, O., Moran P. M., \& Jacobs, C. (2005). Childhood Experience of Care and Abuse Questionnaire (CECA.Q): Validation in a community series. British Journal of Clinical Psychology, 44, 563-581. doi: 10.1348/014466505X35344

Blatt, S. J., Quinlan, D. M., Chevron, E. S., McDonald, C., \& Zuroff, D. (1982). Dependency and self-criticism: Psychological dimensions of depression. Journal of Consulting and Clinical Psychology, 50, 113-124.

Blatt, S. J., Quinlan, D. M., Pilkonis, P. A., \& Shea, T. (1995). Impact of perfectionism and need for approval on the brief treatment of depression. Journal of Consulting and Clinical Psychology, 63,1-7.

Bowlby, J. (1973). Separation, anxiety and anger: Attachment and loss, Vol. 2. London: Hogarth Press.

Costa, P. T., \& McCrae, R. R. (1992). Multiple uses for longitudinal personality data. European Journal of Personality, 6, 85-102.

De Figueiredo, J. M. (1980). Some methodological remarks on transcultural interviewing on psychopathology. Journal of Social Psychiatric, 26 (4), 280-308.

Epstein, M. D. (1995). Thoughts without a thinker. New York: Basic Books.

Folkman, S., \& Moskowitz, J.T. (2000). Stress, positive emotion, and coping. Current Directions in Psychological Science, 9(4), 115-118.

Gilbert, P. (1989). Human nature and suffering. Hove: Lawrence Erlbaum Associates.

Gilbert, P. (2005a). Compassion and cruelty: A biopsychosocial approach. In P. Gilbert (Ed.), Compassion: Conceptualization, research and use in psychotherapy (pp. 9-74). London: Routledge.

Gilbert, P. (2005b). Social mentalities: A biopsychosocial and evolutionary reflection on social relationships. In M. W. Baldwin (Ed.), Interpersonal Cognition (pp. 299-335). New York: Guilford Press.

Gilbert, P., \& Irons, C. (2004). A pilot exploration of the use of compassionate images in a group of self-critical people. Memory, 12, 507-516. doi:10.1080/09658210444000115

Gilbert, P., \& Irons, C. (2005). Focused therapies and compassionate mind training for shame and self-attacking. In P. Gilbert (Ed.), Compassion: Conceptualization, research and use in psychotherapy (pp. 263-325). London: Routledge.

Gilbert, P., \& Procter, S. (2006). Compassionate mind training for people with high shame and self-criticism: Overview and pilot study of a group therapy approach. Clinical Psychology and Psychotherapy, 13, 353-379.

Gilbert, P., Clarke, M., Kempel, S., Miles, J.N., \& Irons, C. (2004a). Criticizing and reassuring oneself: An exploration of forms style and reasons in female students. British Journal of Clinical Psychology, 43, 31-50.

Gilbert, P., Gilbert, J. \& Irons, C. (2004b). Life events, entrapments and arrested anger in depression. Journal of Affective Disorders, 79, 149-160.

Gillath, O., Bunge, S. A., Shaver, P. R., Wendelken, C., \& Mikulincer, M. (2005). Attachmentstyle differences in the ability to suppress negative thoughts: exploring the neural correlates. Neuroimage, 28(4), 835-847.

Goldstein, J., \& Kornfield, J. (1987). Seeking the heart of wisdom: The path of insight meditation. Boston: Shambhala. 
Hayes, S. C., Luoma, J. B., Bond, F. W., Masuda, A., \& Lillis, J. (2006). Acceptance and commitment therapy: model, processes and outcomes. Behavior Research Therapy, 44(1), 1-25.

Irons, C., Gilbert, P., Baldwin, M. W., Baccus, J. R., \& Palmer, M. (2006). Parental recall attachment relating and self-attacking/self-reassurance: Their relationship with depression. British Journal of Clinical Psychology, 45, 297-308. doi:10.1348/014466505X68230

Isen, A. M. (2000). Some perspectives on positive affect and self-regulation. Psychological Inquiry, 11, 184-188.

Leahy, R. L. (2005). A social-cognitive model of validation. In P. Gilbert (Ed.), Compassion: Conceptualization, research and use in psychotherapy (pp. 195-217). London: Brunner-Routledge.

Leary, M. R., Tate, E. B., Adams, C. E., Allen, A. B., \& Hancock, J. (2007). Self-compassion and reactions to unpleasant self-relevant events: the implications of treating oneself kindly. Journal of Personality Social Psychology, 92(5), 887-904.

Mikulincer, M., \& Shaver, P. (2005). Mental representations and attachment security. In M. W. Baldwin (Ed.), Interpersonal cognition (pp. 233-266). New York: Guildford press.

Molino, A. (1998). The couch and the tree: Dialogues in psychoanalysis and Buddhism. New York: North Point Press.

Neff, K. D. (2003a). Self-compassion: An alternative conceptualization of a healthy attitude toward oneself. Self and Identity, 2, 85-102.

Neff, K. D. (2003b). The development and validation of a scale to measure self-compassion. Self and Identity, 2, 223-250.

Neff, K. D., Hsieh, Y., \& Dejitterat, K. (2005). Self-compassion, achievement goals and coping with academic failure. Self and Identity, 4, 263-287.

Neff, K. D., Kirkpatrick, K. L., \& Rude, S.S. (2007a). Self-compassion and adaptive psychological functioning. Journal of Research in Personality, 41, 139-154.

Neff, K. D., Rude, S S., \& Kirkpatrick, K. L. (2007b). An examination of self-compassion in relation to positive psychological functioning and personality traits. Journal of Research in Personality, 41, 908-916.

Neff, K. D., \& Vonk, R. (2009). Self-compassion versus global self-esteem: Two different ways of relating to oneself. Journal of Personality, 77, 23-50.

Nolen-Hoeksema, S. (1991). Responses to depression and their effects on the duration of depressive episodes. Journal of Abnormal Psychology, 100, 569-582.

Nunnally, J. (1978). Psychometric theory ( $2^{\mathrm{a}}$ ed.). USA: McGraw Hill.

Pais-Ribeiro, J., Honrado, A., \& Leal I. (2004). Contribuição para o estudo da adaptação portuguesa das escalas de ansiedade depressão stress de Lovibond e Lovibond. Psychologica, 36, 235-246.

Rubin, J. B. (1996). Psychotherapy and Buddhism: Toward an integration. New York: Plenum Press.

Salovey, P., \& Mayer, J. D. (1990). Emotional intelligence. Imagination, Cognition \& Personality, 9, 185-211.

Shahar, G., Blatt, S. J., Zuroff, D. C., Kupermine, J. P., \& Leadbeater, B. J. (2004). Reciprocal relationship between depressive symptoms and self-criticism (but not dependency) among early adolescent girls (but not boys). Cognitive Therapy and Research, 28, 85-103.

Sheier, M. F., Carver, S. C., \& Bridges, M. W. (1994). Distinguishing optimism from neuroticism (and trait anxiety, self-mastery, and self-esteem): A reevaluation of Life Orientation Test. Journal of Personality and Social Psychology, 6(67), 1063-1078.

Teasdale, J. D., Segal, Z. V., Williams, J. M., Ridgeway, V. A., Soulsby, J. M., \& Lau, M. A. (2000). Prevention of relapse recurrence in major depression by mindfulness-based cognitive therapy. Journal of Consulting \& Clinical Psychology, 68, 615-623. 
Watson, G., Batchelor, S., \& Claxton, G. (Eds.) (1999). The psychology of awakening. London: Rider. Zuroff, D. C., Koestner, R., \& Powers, T. A. (1994). Self-criticism at age 12: A longitudinal study of adjustment. Cognitive Therapy and Research, 4(18), 367-385.

Self-compassion: validation study of the Portuguese version of SelfCompassion Scale and its relationship to adverse childhood experiences, psychopathology and social comparison

Self-compassion represents a strategy for emotional self-regulation positive alternative to self-criticism, with a protective effect in psychopathology. This study explore the psychometric properties of the Portuguese version of Self-Compassion Scale (Self-Compassion Scale, SCS; Neff, 2003), the type of adverse childhood experiences associated negatively with self-compassion and its relation with the social comparison and psychopathology in a sample of 631 college students. SCS has internal consistency, temporal stability, and convergent and divergent validity satisfactory. The results of the 2nd study show that the experiences of criticism, and disinterest on the part of the father (in men) and mother (women) contribute to self-compassion low (high self-criticism and shame as the opposition). Self-compassion is especially important for social acceptance, as well as the existence of a warm mother (for women). The tendency to over-identification with the negative internal experience contributes to depressive symptoms in men, and the face of negative experiences as isolated and unique, the difficulty in being warm and kind with yourself and over-identification contribute to depression in women. Self-compassion and the existence of warm and supportive parental figures are protective factors of depressive symptoms in women.

KEY-WORDS: Self-compassion; Psychometrics; Negative experiences in childhood; Depressive Symptoms.

\section{L'auto-compassion: étude de validation de la version portugaise de l'échelle de l'auto-compassion et sa relation avec les expériences néfas- tes durant l'enfance, la psychopathologie et la comparaison sociale}

L’Auto-Compassion représente une stratégie autorégulation émotionnelle positive alternative l'autocritique, avec un effet amortisseur et protecteur dans le développement de la psychopathologie. Dans cet étude nous présentons les propriétés psychométriques de la version de l'Echèle de l'Auto-Compassion (Self-Compassion Scale, SCS ; Neff, 2003); le type d'expériences adverses de l'enfance plus associées négativement à l'auto-compassion et sa relation avec la comparaison social et la psychopathologie, dans un échantillon de 631 étudiants universitaires. A SCS 
présente des valeurs internement consistants, de stabilité temporel et de validité convergeant et divergeant satisfaisantes. Les résultats du deuxième étude montrent que les expériences de criticisme, et désintérêt pour la part du père (pour les hommes) et pour la part de la mère (pour les femmes) contribuent pour une faible Auto-Compassion. L'Auto-compassion semble être spécialement importante pour l'acceptation (approbation) social, en même temps que l'existence d'une mère chaleureuse (pour les femmes). La tendance à sur-identification avec l'expérience interne négative contribue pour les symptômes dépressifs, pour les hommes et pour les femmes, envisageant les expériences négatives comme isolées et uniques, ont difficulté à être tolérantes et aimables avec eux-mêmes et la sur-identification mène la plupart des fois aux symptômes dépressifs. L'Auto-Compassion et l'existence de figures parentèles assurées et soignantes sont des facteurs de protection pour la symptomatologie dépressive dans les femmes.

MOTS-CLÉS: L’auto-compassion; Psychométrie; Les expériences négatives durant l'enfance; Symptômes dépressifs. 